\title{
Training status affects between-protocols differences in the assessment of maximal aerobic velocity
}

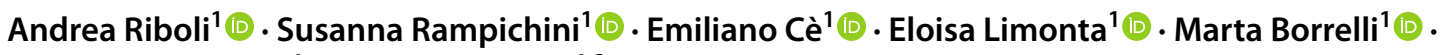 \\ Giuseppe Coratella ${ }^{1}$ (D) Fabio Esposito ${ }^{1,2}$
}

Received: 15 February 2021 / Accepted: 2 July 2021 / Published online: 28 July 2021

(c) The Author(s) 2021

\begin{abstract}
Purpose Continuous incremental protocols $(\mathrm{CP})$ may misestimate the maximum aerobic velocity $\left(\mathrm{V}_{\max }\right)$ due to increases in running speed faster than cardiorespiratory/metabolic adjustments. A higher aerobic capacity may mitigate this issue due to faster pulmonary oxygen uptake $\left(\dot{V} \mathrm{O}_{2}\right)$ kinetics. Therefore, this study aimed to compare three different protocols to assess $\mathrm{V}_{\max }$ in athletes with higher or lower training status.

Methods Sixteen well-trained runners were classified according to higher (HI) or lower (LO) $\dot{V} \mathrm{O}_{2 \max } \dot{V} \mathrm{O}_{2}$-kinetics was calculated across four 5 -min running bouts at $10 \mathrm{~km} \cdot \mathrm{h}^{-1}$. Two CPs $\left[1 \mathrm{~km} \cdot \mathrm{h}^{-1}\right.$ per min $(\mathrm{CP} 1)$ and $1 \mathrm{~km} \cdot \mathrm{h}^{-1}$ every 2-min (CP2)] were performed to determine $\mathrm{V}_{\max } \dot{V} \mathrm{O}_{2 \max }$, lactate-threshold and submaximal $\dot{V} \mathrm{O}_{2} /$ velocity relationship. Results were compared to the discontinuous incremental protocol (DP).

Results $\mathrm{V}_{\max }, \dot{V} \mathrm{O}_{2 \max }, \dot{V} \mathrm{CO}_{2}$ and VE were higher [ $\left(P<0.05\right.$,(ES:0.22/2.59)] in HI than in LO. $\dot{V} \mathrm{O}_{2}$-kinetics was faster $\left[P<0.05\right.$, (ES:-2.74/ - 1.76)] in HI than in LO. $\dot{V} \mathrm{O}_{2} /$ velocity slope was lower in HI than in LO $[(P<0.05$, (ES:- $1.63 /-0.18)]$. $\mathrm{V}_{\text {max }}$ and $\dot{V} \mathrm{O}_{2}$ /velocity slope were $\mathrm{CP} 1>\mathrm{CP} 2=\mathrm{DP}$ for $\mathrm{HI}$ and $\mathrm{CP} 1>\mathrm{CP} 2>\mathrm{DP}$ for LO. A lower $[P<0.05$, (ES:0.53/0.75)] $\mathrm{V}_{\text {max }}$-difference for both CP1 and CP2 vs DP was found in HI than in LO. $\mathrm{V}_{\text {max }}$-differences in CP1 vs DP showed a large inverse correlation with $\mathrm{V}_{\max }, \dot{V} \mathrm{O}_{2 \max }$ and lactate-threshold and a very large correlation with $\dot{V} \mathrm{O}_{2}$-kinetics.

Conclusions Higher aerobic training status witnessed by faster $\dot{V} \mathrm{O}_{2}$ kinetics led to lower between-protocol $\mathrm{V}_{\text {max }}$ differences, particularly between CP2 vs DP. Faster kinetics may minimize the mismatch issues between metabolic and mechanical power that may occur in CP. This should be considered for exercise prescription at different percentages of $\mathrm{V}_{\max }$.
\end{abstract}

Keywords $\dot{V} \mathrm{O}_{2}$ kinetics $\cdot$ Maximal aerobic power $\cdot$ Maximum oxygen uptake $\cdot$ Incremental test $\cdot$ Running velocity . Aerobic capacity

\section{Abbreviations}

HI

LO

CP1

$\mathrm{CP} 2$

DP
Group with high $\dot{V} \mathrm{O}_{2 \max }$

Group with low $\dot{V} \mathrm{O}_{2 \max }$

Continuous incremental protocol

[1 km.h-1 per min]

Continuous incremental protocol

[ $1 \mathrm{~km} \cdot \mathrm{h}-1$ every $2 \mathrm{~min}$ ]

Discontinuous incremental protocol

Communicated by Guido ferrati.

Andrea Riboli

riboliandrea@outlook.com

1 Department of Biomedical Sciences for Health (SCIBIS), University of Milan, Via G. Colombo 71, 20133 Milan, Italy

2 IRCCS, Istituto Ortopedico Galeazzi, Via R. Galeazzi 4, 20161 Milan, Italy
$\dot{V} \mathrm{O}_{2 \max }$ $\dot{V} \mathrm{O}_{2} /$ Velocity slope

$\dot{V} \mathrm{O}_{2}$ kinetics

Vmax

$\dot{V} \mathrm{CO}_{2}$

RER

$\mathrm{SaO}_{2}$

VE

BLa-

RPE

ANOVA

ES

95\% CI
Maximum oxygen uptake

Regression analysis of the $\dot{V} \mathrm{O}_{2}$ vs velocity relationship at submaximal workloads $\dot{\mathrm{V}} \mathrm{O}_{2}$-transition from rest to steady-condition The velocity associated with maximum oxygen uptake Carbon dioxide production Respiratory exchange ratio Arterial $\mathrm{O}_{2}$ saturation Expiratory ventilation Blood lactate concentration Rate of perceived exertion Analysis of variance Effect size 95\% Confidence intervals 


\section{Introduction}

A successful aerobic performance depends on several physiological, biomechanical, and psychological factors (Bentley et al. 2007; Coyle 1995). Among physiological aspects, a high maximum pulmonary oxygen uptake $(\dot{V}$ $\mathrm{O}_{2 \max }$ ), the ability to maintain a long time to exhaustion at $\mathrm{VO}_{2 \max }$, a faster $\dot{V} \mathrm{O}_{2}$-transition from rest to steadycondition ( $\dot{V} \mathrm{O}_{2}$ kinetics), a higher lactate threshold and a low $\mathrm{O}_{2}$ cost of running are the main parameters of aerobic performance (Poole and Richardson 1997; Coyle 1995; Poole and Jones 2012).

Also the maximum aerobic velocity $\left(\mathrm{V}_{\max }\right)$, defined as the minimum velocity capable to elicit $\dot{V} \mathrm{O}_{2 \max }$ when considering only the completion of the primary phase of $\dot{V} \mathrm{O}_{2}$-on kinetics (Ferretti 2015), is reported as a strong marker of running performance (Bentley et al. 2007) and it integrates both metabolic and biomechanical aspects of running into a single factor (Buchheit and Laursen 2013). In elite aerobic athletes, a higher $\mathrm{V}_{\max }$ reflects a greater capacity to utilize the aerobic metabolic pathways across several sports (Noakes 1988; Pedro et al. 2013; Ziogas et al. 2011; Rampinini et al. 2007).

$\dot{V} \mathrm{O}_{2 \max }$ and $\mathrm{V}_{\text {max }}$ are generally determined using different incremental running protocols (Kuipers et al. 2003; Riboli et al. 2017), among which continuous or discontinuous tests that may vary in work rate increments and stage duration (Billat et al. 1996; Kuipers et al. 2003; Riboli et al. 2017). Discontinuous incremental protocols (DP) are characterized by constant work rates interspersed by resting periods (Duncan et al. 1997; Riboli et al. 2017). DP permits to reach an equilibrium between the cardiorespiratory and metabolic systems and the work rate when lasting at least three minutes to achieve a steady-state condition (Poole and Jones 2012). However, the long overall duration of DP would markedly lengthen the whole testing phase, thus affecting the possibility to test several athletes within one single session, as often required in sports practice. Conversely, incremental continuous protocols (CP) last short overall duration and they have been shown as a valid and reliable method to determine $\dot{V} \mathrm{O}_{2 \max }$ despite the submaximal physiological adjustments cannot be reached as in DP due to increments in work rate faster than cardiorespiratory and metabolic adjustments (Riboli et al. 2017, 2021). Despite in some intermittent protocols with very low workload $v s$ recovery ratio $\dot{V} \mathrm{O}_{2 \max }$ may not be reached (Vinetti et al. 2017), previous studies using CP and DP showed that $\dot{V} \mathrm{O}_{2 \max }$ was found to be independent from the protocol adopted (Kuipers et al. 2003; Riboli et al. 2017, 2021). Conversely, testing protocols with shorter stage duration may lead to higher $\mathrm{V}_{\max }$ (Riboli et al. 2017; Kuipers et al. 2003; Adami et al. 2013). Given that $\mathrm{V}_{\max }$ is currently utilized to prescribe or monitor training routines (Buchheit and Laursen 2013; Riboli et al. 2021), a precise $\mathrm{V}_{\max }$ assessment may allow coaches to manipulate accurately the physiological load during running exercises as a percentage of $\mathrm{V}_{\max }$ (Buchheit and Laursen 2013; Riboli et al. 2021). For instance, $90-110 \%$ of $\mathrm{V}_{\max }$ are suggested for long-interval exercises, $110-130 \% \mathrm{~V}_{\max }$ for short-intervals exercises, $130-160 \% \mathrm{~V}_{\max }$ for repeated sprint training and $>160 \% \mathrm{~V}_{\max }$ for sprint interval training (Buchheit and Laursen 2013). Therefore, a precise $\mathrm{V}_{\max }$ assessment should be carefully taken into account for athletes' testing and training prescription (Riboli et al. 2017; Bentley et al. 2007).

Athletes with a high aerobic capacity (HI), such as longand middle-distance runners, are qualified by greater physiological characteristics in terms of high $\dot{V} \mathrm{O}_{2 \max }$ and fast $\dot{V} \mathrm{O}_{2}$ kinetics (Coyle 1995) than in individuals with lower aerobic capacity (LO). A high $\dot{V} \mathrm{O}_{2 \max }$ represents, indeed, a pronounced maximal pulmonary, cardiovascular, metabolic and muscular capacity to uptake, transport and utilize $\mathrm{O}_{2}$ (Poole and Richardson 1997). Moreover, rapid $\dot{V} \mathrm{O}_{2}$ kinetics may lead to a smaller $\mathrm{O}_{2}$ deficit and a reduced intracellular perturbation, thus reflecting greater exercise tolerance (Poole and Jones 2012; Dupont et al. 2005) and endurance performance (Poole and Jones 2012). These characteristics in $\mathrm{HI}$ may therefore lower or even minimize the misestimating issue that may occur in CP because of their faster $\dot{V} \mathrm{O}_{2}$ kinetics.

With this in mind, the present study aimed to investigate how aerobic training status may affect $\mathrm{V}_{\max }$ assessment during CPs vs DP in two groups of athletes, characterized by different aerobic training conditions. Should HI in the investigated group demonstrate faster $\dot{V} \mathrm{O}_{2}$ kinetics due to their greater ability of the cardiorespiratory and metabolic systems to adjust to continuous increases in work rate typical of $\mathrm{CP}$, the $\mathrm{V}_{\max }$ misestimating issue may be minimized, when comparing their CPs to DP results.

\section{Materials and methods}

\section{Participants}

Sixteen well-trained middle and long-distance runners (age: $22.1 \pm 1.8$ years; stature: $1.75 \pm 0.05 \mathrm{~m}$; body mass: $70.3 .7 \pm 3.7 \mathrm{~kg}$; mean \pm standard deviation) volunteered to participate in the study and were classified into two groups, according to their higher (HI) or lower (LO) $\dot{V} \mathrm{O}_{2 \max }$ and the International Physical Activity Questionnaire (IPAQ). All participants met the following criteria: (a) more than four years of systematic training and (b) no injuries in the last year. The ethics committee of the local University approved the study (protocol \#102/14) which was performed in 
accordance with the principles of the Declaration of Helsinki (1964 and updates). All participants gave their written consent after a full explanation of the purpose of the study and the experimental design.

\section{Study design}

To test the current hypothesis, two incremental continuous protocols with different stage durations $(\mathrm{CP})$ were performed and compared to a discontinuous incremental protocol (DP). The present study spanned over a maximum of 3 weeks. The participants reported to the laboratory five times, separated by at least $72 \mathrm{~h}$. During the first visit, they were familiarized with the experimental procedures. During the second session, they performed a continuous incremental protocol ( $1 \mathrm{~km} \cdot \mathrm{h}^{-1}$ per minute) to determine $\dot{V} \mathrm{O}_{2 \max }$ and to complete the IPAQ. Within the remaining three sessions, the participants randomly underwent the three experimental conditions (two continuous and one discontinuous incremental protocols). Within each testing-session, an initial 5-min submaximal bout at $10 \mathrm{~km} \cdot \mathrm{h}^{-1}$ was modelled to determine the on-transient $\dot{V} \mathrm{O}_{2}$ kinetics. Participants were instructed to avoid any form of strenuous exercise in the three days before each session. In addition, they were asked to have their last standardized meal at least three hours before each session. Finally, they were requested to abstain from ergogenic and caffeinated beverages before testing.

Participants were split subsequently into two groups, according to their $\dot{V} \mathrm{O}_{2 \max }$ normalized per body mass $\left(\mathrm{ml} \cdot \mathrm{kg}^{-1} \cdot \mathrm{min}^{-1}\right)$ and their training routines (i.e., $n$ of training sessions per week). The first HI group was characterized by a higher $\dot{V} \mathrm{O}_{2 \max }$ and more than five training sessions per week. The second LO group was characterized by a lower $\dot{V} \mathrm{O}_{2 \max }$ and no more than three training sessions per week.

\section{Experimental procedures}

All tests were conducted approximately at the same time of the day in a climate-controlled laboratory (constant temperature of $20 \pm 1{ }^{\circ} \mathrm{C}$ and relative humidity of $50 \pm 5 \%$ ). All tests were carried out on a treadmill ergometer (RAM s.r.l., mod. $770 \mathrm{~S}$, Padova, Italy) with a $1 \%$ positive slope. Blood lactate concentration $\left(\mathrm{BLa}^{-}\right)$was assessed by a spectrophotometric system (Lactate Pro LT-1710, Arkray, Kyoto, Japan). The lactate analyzer was calibrated before each protocol to guarantee consistent data. $\dot{V} \mathrm{O}_{2 \max }$, expiratory ventilation, carbon dioxide production and respiratory exchange ratio were measured during each protocol by a gas analyzer cart (Cosmed, mod. Quark $b 2$, Rome, Italy). The device was calibrated before each test with gas mixtures of known concentration $\left(\mathrm{O}_{2} 16 \%, \mathrm{CO}_{2} 5 \%\right.$, balance $\left.\mathrm{N}_{2}\right)$. Heart rate was monitored continuously using a heart rate monitor (Polar Electro Oy, mod. S810i, Kempele, Finland). Arterial
$\mathrm{O}_{2}$ saturation was determined by a finger-tip infrared oxymeter (NONIN Medical, mod. 3011, Minneapolis, MN). At the end of the test, the rate of perceived exertion (RPE) was determined using the 6-20 Borg scale for general, respiratory and muscular fatigue. The participants were strongly encouraged by the operators to perform each test up to their maximum exercise capacity.

Continuous Incremental Protocol 1 (CP1). After 5 min of baseline measurements, while standing on the treadmill, the participants warmed up at $10 \mathrm{~km} \cdot \mathrm{h}^{-1}$ for $5 \mathrm{~min}$. Then, the running speed was increased progressively by $1 \mathrm{~km} \cdot \mathrm{h}^{-1}$ per minute until volitional exhaustion. $\mathrm{BLa}^{-}$was measured at baseline, at the end of each stage and after 1, 3 and 5 min of passive recovery. The achievement of $\mathrm{VO}_{2 \max }$ was identified as the plateauing of $\dot{V} \mathrm{O}_{2}\left(<2.1 \mathrm{ml} \cdot \mathrm{kg}^{-1} \cdot \mathrm{min}^{-1}\right.$ increase) despite an increase in workload (Poole and Richardson 1997). If the above-stated criterion and/or secondary criteria to establish $\dot{V} \mathrm{O}_{2 \max }$ (Poole et al. 2008) were not fulfilled, the participants were asked to perform a further constant-speed test equal or higher than the highest speed achieved at the end of the incremental test, as strongly recommended (Rossiter et al. 2006). $\dot{V} \mathrm{O}_{2}$, carbon dioxide production, expiratory ventilation, $\mathrm{O}_{2}$ saturation and respiratory exchange ratio were averaged during the last $30 \mathrm{~s}$ of each step at submaximal workload and over the last $30 \mathrm{~s}$ before exhaustion. $\mathrm{V}_{\max }$ was determined as the minimal running velocity that elicited $\dot{V} \mathrm{O}_{2 \max }$ over a period of 30 s (Billat et al. 1996). If a stage could not be completed, the $\mathrm{V}_{\max }$ was calculated according to a previously published equation (Kuipers et al. 2003) $\left[\mathrm{V}_{\max }=\mathrm{V}_{\text {completed }}+\mathrm{t} / \mathrm{T} \mathrm{x}\right.$ speed increment], in which $\mathrm{V}_{\text {completed }}$ is the running speed of the last stage that was completed, $t$ the number of seconds that the uncompleted running stage could be sustained, $\mathrm{T}$ the number of seconds required to complete the stage, and speed increment is the speed load increment in $\mathrm{km} \cdot \mathrm{h}^{-1}$.

Continuous Incremental Protocol 2 (CP2). CP2 followed the same experimental procedures as $\mathrm{CP} 1$, but with the increases in treadmill running speed of $1 \mathrm{~km} \cdot \mathrm{h}^{-1}$ every two minutes. As for $\mathrm{CP} 1, \dot{V} \mathrm{O}_{2}$, carbon dioxide production, expiratory ventilation, $\mathrm{O}_{2}$ saturation, and respiratory exchange ratio were averaged during the last $30 \mathrm{~s}$ of each step at submaximal workload and over the last $30 \mathrm{~s}$ before exhaustion. $\mathrm{V}_{\max }$ was determined as the minimal running velocity that elicited $\dot{V} \mathrm{O}_{2 \max }$ over a period of $30 \mathrm{~s}$ (Billat et al. 1996).

Discontinuous Incremental Protocol (DP). DP protocol involved five workloads of 4 min each, interspersed by at least $5 \mathrm{~min}$ of recovery (Bernard et al. 2000). The optimal stage duration suggested for DPs is still questioned (Bernard et al. 2000). Although some authors suggested that it should be around 6-8 min (Bernard et al. 2000), it was criticized that relatively long stage duration could result in premature fatigue and suggested that 4-6 min could be suitable for this purpose (Bentley et al. 2007; Kuipers et al. 2003; 
Bernard et al. 2000). Since shorter test duration is strongly advocated during in-field practice, a 4-min stage duration was used here.

Baseline measurements were recorded with the participants standing on the treadmill. The first two workloads were set at 8 and $10 \mathrm{~km} \cdot \mathrm{h}^{-1}$ for all participants. The following three workloads were tailored for each participant according to the individual cardiorespiratory responses to the first two workloads and considering the theoretical maximum heartrate determined (Bernard et al. 2000). Firstly, based on the $\dot{V} \mathrm{O}_{2}$ and the heart-rate recorded during the first two stages, a sub-maximal linear regression was determined up to the predicted peak heart rate, to predict the speed corresponding to possible exhaustion (Bernard et al. 2000). Then, the third, the fourth and the fifth workloads corresponded to approximately $80 \%, 90 \%$ and $105 \%$ of the predicted peak workload, respectively. The fourth and the fifth workloads were recalculated using the heart-rate and $\dot{V} \mathrm{O}_{2}$ recorded during the third and the fourth stage, respectively. The last stage was tailored to let the participants maintain the task for at least four minutes (Bernard et al. 2000). The blood lactate concentration was measured at baseline and after 1, 3 and 5 min of passive recovery for each workload, and the peak blood lactate was inserted into the data analysis. $\dot{V} \mathrm{O}_{2}$, carbon dioxide production, expiratory ventilation, $\mathrm{O}_{2}$ saturation and respiratory exchange ratio were determined as the average value of the last (fourth) minute during each workload (Poole and Richardson 1997). $V_{\max }$ was extrapolated from the regression analysis equation of $\dot{V} \mathrm{O}_{2}$ as a function of running velocity at submaximal workloads below the lactate threshold (Bernard et al. 2000; Riboli et al. 2017).

\section{Lactate threshold, $\dot{\mathrm{VO}}_{2} /$ Velocity slope at submaximal exercise and $\mathrm{VO}_{2}$ kinetics}

Lactate threshold was determined by the $\mathrm{D}_{\mathrm{MAX}}$ method, according to which it was identified as the point on the third-order polynomial curve that yielded the maximal perpendicular distance to the straight line formed by the two end data points (Riboli et al. 2019). Similar to the previous study, lactate threshold calculated from CP1 was utilized to limit the range of exercise during which the $\dot{V} \mathrm{O}_{2}$ vs running velocity relationship at submaximal exercise was considered (Riboli et al. 2017).

$\dot{V} \mathrm{O}_{2}$ /Velocity slope: the $\dot{V} \mathrm{O}_{2}$ /Velocity slope was calculated as the regression analysis of the $\dot{V} \mathrm{O}_{2} v s$ velocity relationship at submaximal workloads below lactate threshold for CP1, CP2 and DP (Anderson 1996; Fletcher et al. 2009).

$\dot{V} \mathrm{O}_{2}$ kinetics. The on-transient $\dot{V} \mathrm{O}_{2}$ kinetics were modelled after four different bouts of 5-min submaximal exercise $\left(10 \mathrm{~km} \cdot \mathrm{h}^{-1}\right.$, moderate intensity, below lactate threshold) to avoid any effect of the slow component phenomenon (Jones et al. 2011). The influence of the inter-breath noise was reduced averaging the results of four identical tests in each participant (Lamarra et al. 1987). Each abnormal breath (e.g., different from the mean of the adjacent four data point by more than three times the standard-deviation of those four point, were excluded (Dupont et al. 2005). To increase the time resolution the breath-by-breath $\dot{V} \mathrm{O}_{2}$ data were subsequently linearly interpolated, and the four data sets were averaged together to produce a single response for each subject. This procedure was previously established to reduce the noise of the $\dot{V} \mathrm{O}_{2}$ signal and to provide the highest confident results (Poole and Jones 2012). The on-transient of the $\dot{V}$ $\mathrm{O}_{2}$ kinetics were modelled as previously proposed (Barstow and Mole 1991). The time-delay of the cardiodynamic-phase and the time-constant of the primary-phase (i.e., the time to reach $63 \%$ of the $\dot{V} \mathrm{O}_{2}$ steady-state of the $\dot{V} \mathrm{O}_{2}$ kinetics were calculated to determine the amplitude of $\dot{V} \mathrm{O}_{2}$ from baseline to steady-state (Poole and Jones 2012). Then, the mean response time of the on-transition $\dot{V} \mathrm{O}_{2}$ kinetics as the sum of time-delay and time-constant was calculated. The time-delay, the time-constant and the mean response time were thereafter inserted into data analysis.

\section{Statistical analysis}

Statistical analysis was performed using a statistical software package (Sigma Plot for Windows, v 12.5, Systat Software Inc., San Jose, CA, USA). To check the normal distribution of the sampling, a Kolgomorov-Smirnov test was applied. A one-way analysis of variance (ANOVA) for repeated measures was used also to assess significant differences in $\mathrm{V}_{\max }$, $\dot{V} \mathrm{O}_{2 \max }$, carbon dioxide production, respiratory exchange ratio, arterial $\mathrm{O}_{2}$ saturation, heart-rate, expiratory ventilation, blood lactate concentration, $\dot{V} \mathrm{O}_{2} /$ Velocity slope (for both slope and intercept of the submaximal regression analysis equation), $\dot{V} \mathrm{O}_{2}$ kinetics (time-delay, time-constant and mean-response time), general-, muscular-, and respiratoryRPE between CP1, CP2 and DP. For all pairwise multiple comparisons, a post-hoc Shapiro-Wilk test was applied. A regression analysis was used to assess the relationship between $\dot{V} \mathrm{O}_{2}$ and running velocity at submaximal exercise. The magnitude of the changes was assessed using Cohen's standardized effect size (ES) with $95 \%$ confidence intervals $(95 \%$ CI). Effect size with 95\% CI was calculated and interpreted as follows: $<0.20$ : trivial; 0.20-0.59: small; 0.60-1.19: moderate; $1.20-1.99$ : large $; \geq 2.00$ : very large (Hopkins et al. 2009). Pearson's product moment and 95\% CI were utilized to assess the relationship among protocols for $\mathrm{V}_{\max }$. The correlation coefficients were interpreted as follows: $r<0.1$ trivial; $0.1 \leq r<0.3$ small; $0.3 \leq r<0.5$ moderate $; 0.5 \leq r<0.7$ large $; 0.7 \leq r<0.9$ very large $; 0.9 \leq r<1$ nearly perfect. Statistical significance was set at an $\alpha$ level of 0.05 . Unless otherwise stated, all values are presented as mean \pm standard deviation (SD). 


\section{Results}

\section{Between-groups differences}

As shown in Table 1, $\mathrm{V}_{\max }[P<0.001$, (ES:1.85/2.59)], $\dot{V} \mathrm{O}_{2 \max }\left[P<0.001\right.$, (ES:0.85/1.07)], $\mathrm{VCO}_{2}[P<0.001$, (ES:0.22/0.61)] and VE $[P<0.001$, (ES:0.57/0.82] were small to very largely higher in $\mathrm{HI}$ than $\mathrm{LO}$ within-each protocol (CP1, CP2 and DP) (Table 1). No between-groups differences $(P>0.05)$ in respiratory exchange ratio, arterial $\mathrm{O}_{2}$ saturation, heart rate, $\mathrm{BLa}^{-}{ }_{\text {peak }}$, general-, respiratory-, and muscular-RPE were found.

The lactate threshold calculated in CP1 was moderately [ES:1.99(CI:0.79/3.19)] higher $(P<0.001)$ in HI [17.8(1.1)] than LO [16.1(0.3)]. Overall, the submaximal regression analysis of $\dot{V} \mathrm{O}_{2}$ /velocity relationship for CP1, CP2 and DP was less steep $(P<0.05)$ in HI than LO (Fig. 1); in details, the intercept of the submaximal regression analysis in $\dot{V} \mathrm{O}_{2} /$ velocity relationship $\left(\dot{V} \mathrm{O}_{2} /\right.$ velocity intercept) was moderately to largely (ES:-0.86/1.63) lower $(P<0.05)$ in $\mathrm{HI}$ than $\mathrm{LO}$ within-each protocol (CP1, CP2 and DP). The slope of the submaximal regression analysis in $\dot{V} \mathrm{O}_{2} /$ velocity relationship $\left(\dot{V} \mathrm{O}_{2} /\right.$ velocity slope) showed trivial to moderate (ES:-0.18/0.83) not significant $(P>0.05)$ differences between $\mathrm{HI}$ and $\mathrm{LO}$ in CP1, CP2 and DP.

The $\dot{V} \mathrm{O}_{2}$ kinetics was largely to very largely (ES: -2.74/-1.76) faster $(P>0.05)$ in HI than LO: despite small [ES:-0.36(CI: -1.35/0.63] non-significant differences $(P>0.05)$ in time-delay, HIGH showed a large [ES:-1.76(CI:-2.92/-0.61] and very-large [ES:2.74(-4.10/-1.37)] difference with a faster time-constant and mean-response time than LO, respectively (Fig. 2).

\section{Between-protocols differences at maximal exercise}

As shown in Table 1, $\mathrm{V}_{\max }$ was largely higher in CP1 $v s$ DP for both HI $[P<0.001$, ES:1.96(0.77/3.16) $]$ and LO $[P<0.001$, ES: $1.84(0.67 / 3.01)]$. In CP1 vs CP2, $\mathrm{V}_{\max }$ was largely higher for $\mathrm{HI}[P<0.001$, ES: 1.73 , CI: $0.58 / 2.88)]$ and moderately higher for LO $[P=0.006$, ES: $1.11(0.06 / 2.17]$. In CP2 vs DP, $\mathrm{V}_{\max }$ was moderately higher for LO $[P=0.039$, ES: $0.75(-0.26 / 1.76)]$, while small not significant $\mathrm{V}_{\max }$-difference for $\mathrm{HI}[P=0.102$, ES: $0.30(-0.68 / 1.29)]$ were retrieved.

No between-protocol (CP1 vs CP2 vs DP) differences for maximum $\dot{\mathrm{V}} \mathrm{O}_{2}, \mathrm{VCO}_{2}, \mathrm{RER}, \mathrm{SaO}_{2}, f_{\mathrm{H}}, \mathrm{VE}$ and $\mathrm{BLa}^{-}$peak were found for both HI and LO. Similarly, no between-protocol differences in general-, respiratory- and muscular-RPE were found.

\section{Between-protocols differences at submaximal exercise}

As shown in Fig. 1, $\quad \dot{V} \mathrm{O}_{2}$ /velocity slope showed a moderate difference in CP1 vs DP for HI $[P=0.003$, ES:-0.85(-1.88/-0.17)] and a large difference for LO $[P=0.002$, ES: $-1.75(-2.91 /-0.60)]$. In CP1 vs CP2, $\dot{V} \mathrm{O}_{2} /$ velocity slope showed a small difference for $\mathrm{HI}[P=0.003$,

Table 1 Cardiorespiratory, metabolic, and perceptual variables at maximum exercise for HI and LO groups. Mean (SD)

\begin{tabular}{|c|c|c|c|c|c|c|}
\hline & \multicolumn{3}{|l|}{ HI } & \multicolumn{3}{|l|}{ LO } \\
\hline & CP1 & $\mathrm{CP} 2$ & DP & $\mathrm{CP} 1$ & $\mathrm{CP} 2$ & DP \\
\hline $\mathrm{V}_{\max }\left(\mathrm{km} \cdot \mathrm{h}^{-1}\right)$ & $22.1(1.2)^{*}$ & $19.9(1.2)^{*, * *}$ & $19.5(1.3)$ & $19.1(1.8)^{*}{ }^{* * * *}$ & $17.2(1.4)^{*, * *, * * * *}$ & $16.2(1.1)^{* * * *}$ \\
\hline$\dot{V} \mathrm{O}_{2}\left(\mathrm{ml} \cdot \mathrm{min}^{-1}\right)$ & $4169.6(478.9)$ & $4132.8(134.2)$ & $4158.8(473.5)$ & $3912.0(442.6)^{* * * *}$ & $3907.8(356.4)^{* * *}$ & $3895.3(424.9)^{\S}$ \\
\hline$\dot{V} \mathrm{O}_{2}\left(\mathrm{ml} \cdot \mathrm{kg} \cdot \mathrm{min}^{-1}\right)$ & $59.2(5.2)$ & $58.7(5.4)$ & $59.1(5.2)$ & $54.6(4.8)^{* * * *}$ & $54.4(4.1)^{* * *}$ & $54.5(2.5)^{* * * *}$ \\
\hline$\dot{V} \mathrm{CO}_{2}\left(\mathrm{ml} \cdot \mathrm{min}^{-1}\right)$ & $4581.9(510.4)$ & $4492.8(110.8)$ & $4665.2(442.0)$ & $4465.8(494.7)^{* * * *}$ & $4366.4(473.0)^{* * *}$ & $4371.7(463.0)^{* * *}$ \\
\hline RER & $1.10(0.09)$ & $1.09(0.03)$ & $1.13(0.04)$ & $1.13(0.06)$ & $1.11(0.06)$ & $1.12(0.06)$ \\
\hline $\mathrm{SaO}_{2}(\%)$ & $89.8(2.7)$ & $89.6(1.8)$ & $89.8(2.7)$ & $91.0(1.7)$ & $90.6(2.7)$ & $90.1(2.7)$ \\
\hline$f_{\mathbf{H}}$ (beats $\cdot \min ^{-1}$ ) & $188.0(10.0)$ & $188(10.0)$ & $186.0(7.0)$ & $189.0(1.0)$ & $188.0(5.0)$ & $187.0(7.0)$ \\
\hline$\dot{V} \mathrm{E}\left(1 \cdot \min ^{-1}\right)$ & $166.9(19.4)$ & $164.1(4.2)$ & $163.3(10.9)$ & $155.1(19.4)^{* * * *}$ & $156.2(14.9)^{* * *}$ & $155.4(7.0)^{* * *}$ \\
\hline $\mathrm{BLa}^{-}$peak $(\mathrm{mM})$ & $13.0(4.0)$ & $11.4(2.3)$ & $12.5(2.1)$ & $11.4(1.3)$ & $11.9(1.0)$ & $11.8(0.8)$ \\
\hline General RPE (au) & $18.2(1.2)$ & $17.9(1.3)$ & $18.0(1.3)$ & $18.1(2.1)$ & $18.3(1.5)$ & $18.9(1.2)$ \\
\hline Respiratory RPE (au) & $18.5(1.2)$ & $17.7(1.4)$ & $17.7(1.4)$ & $17.6(3.1)$ & $17.8(1.7)$ & $18.8(1.0)$ \\
\hline Muscular RPE (au) & $17.4(1.5)$ & $17.9(1.8)$ & $18.4(1.5)$ & $17.8(1.7)$ & $17.9(2.6)$ & $18.1(1.9)$ \\
\hline
\end{tabular}

$V_{\max }$ velocity associated with maximum oxygen uptake; $\dot{V} \mathrm{O}_{2}$ oxygen uptake; $\dot{V} C \mathrm{O}_{2}$ carbon dioxide production; $R E R$ respiratory exchange ratio; $\mathrm{SaO}_{2}$ arterial $\mathrm{O}_{2}$ saturation; $f_{\mathrm{H}}$ heart rate frequency; $\dot{\mathrm{V}}$, expiratory ventilation; $\mathrm{BLa}^{-}$peak peak blood lactate concentration; and rate of perceived exertion (RPE) at general, respiratory, and muscular level. Variables were determined at maximum exercise in the three testing conditions (CP1, continuous ramp 1; $\mathrm{CP} 2$, continuous ramp 2; $\mathrm{DP}$, discontinuous protocol).

${ }^{*} \mathrm{P}<0.05$ vs DP; ${ }^{* *} \mathrm{P}<0.05$ vs $\mathrm{CP} 1 ;{ }^{* * *} \mathrm{P}<0.05$ vs $\mathrm{HI}$ 


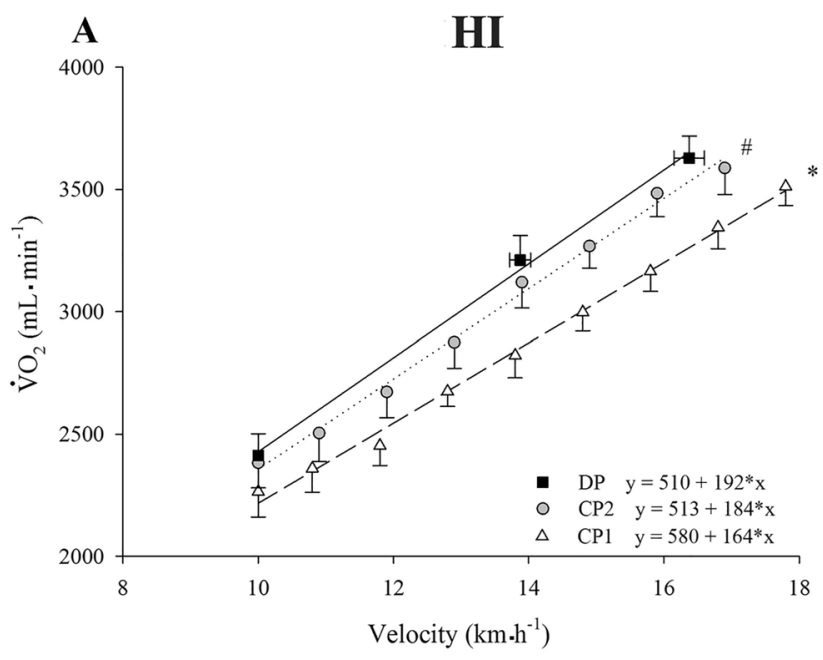

Fig. 1 The $\dot{V} \mathrm{O}_{2}$ as a function of running velocity at submaximal work rates (below the velocity corresponding to the lactate threshold calculated in CP1 condition) for both HI and LO. The solid, dashed and dotted lines represent the regression lines for the discontinuous (DP), continuous protocol with $1 \mathrm{~km} \cdot \mathrm{h}^{-1}$ increment per minute (CP1) and

ES:-.48(-1.48/0.51)] and very large difference for LO $[P=0.007$, ES: $-5.97(-8.26 /-3.68)]$. In CP2 vs DP, $\dot{V} \mathrm{O}_{2} /$ velocity slope showed a trivial no-significant difference for $\mathrm{HI}[P=0.283$, ES: $-0.20(-1.18 / 0.79)]$ and a very large difference for LO $[P=0.016$, ES: $-2.33(-3.60 /-1.06)]$.

In $\mathrm{CP} 1$ vs DP, $\dot{V} \mathrm{O}_{2}$ /velocity intercept showed a small difference for HI $[P<0.001$, ES:0.21(-0.78/1.19)] and a moderate difference for LO $[P=0.002$, ES: 0.99(0.05/2.03)]. In $\mathrm{CP} 1$ vs $\mathrm{CP} 2, \dot{V} \mathrm{O}_{2} /$ velocity intercept showed a trivial difference for HI $[P=0.010$, ES:0.10(-0.88/1.08)] and a moderate difference for LO $[P=0.015$, ES:0.61 (-0.36/1.60)]. In CP2 vs DP, $\dot{V} \mathrm{O}_{2}$ /velocity intercept showed a trivial no-significant differences for HI $[P=0.348$, ES: $0.00(-0.98 / 0.98)]$ and a very large difference for LO $[P<0.001$, ES: $1.51(0.40 / 2.62)]$.

\section{Between-protocol $V_{\max }$ correlations}

Very large between-protocol correlations for $\mathrm{V}_{\max }$ were calculated for HI ( $r=0.73, r=0.84$, and $r=0.73$ for CP1 $v s \mathrm{DP}$, $\mathrm{CP} 2$ vs DP and CP1 vs CP2, respectively $P<0.05$ ). Moderate to large between-protocol correlations for $\mathrm{V}_{\max }$ were calculated for LO $(r=0.49, r=0.68$, and $r=0.79$ for CP1 vs $\mathrm{DP}, \mathrm{CP} 2$ vs $\mathrm{DP}$ and $\mathrm{CP} 1$ vs $\mathrm{CP} 2$, respectively $\mathrm{P}<0.05)$.

\section{Relationship between training status and between-protocol differences}

The percentage of the $\mathrm{V}_{\max }$ in CP1 vs DP showed a small $[P=0.045$, ES: $-0.53(-1.56 / 0.46)]$ difference between HI

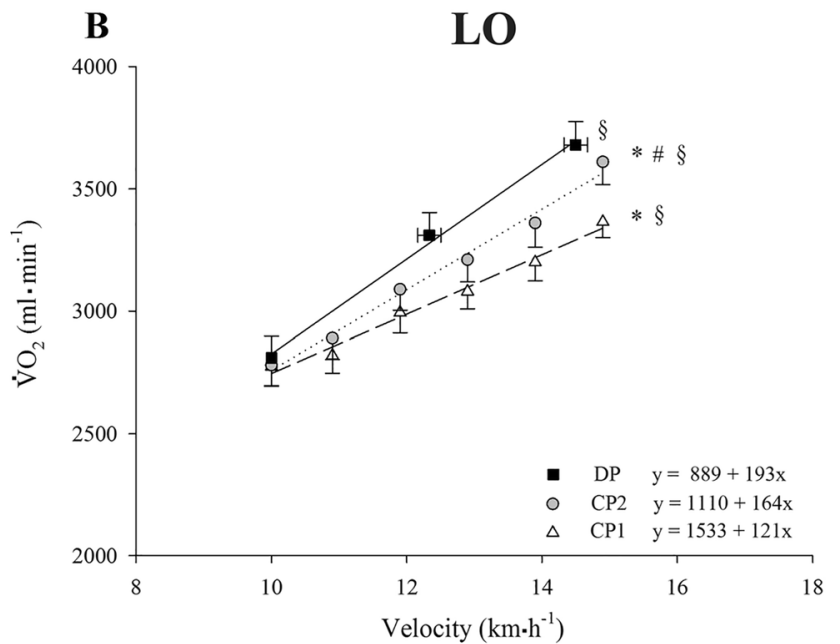

$2 \mathrm{~km} \cdot \mathrm{h}^{-1}$ increment every $2 \mathrm{~min}(\mathrm{CP} 2)$, respectively. Panel A and $\mathbf{B}$ show HIGH and LOW group, respectively. Regression equations $(y=a \cdot b x)$ and correlation coefficients are also reported. $* P<0.05$ $v s$ DP for slope and intercept of the regression equation, ${ }^{\#} P<0.05 v s$ $\mathrm{CP} 1$ for slope of the regression equation, ${ }^{\S} P<0.05 v s$ HI for the intercept of the regression equation

and LO $[+13.3(5.4) \%$ and $+17.9(10.2) \%$, respectively $]$ and a moderate $[P=0.032$, ES: $-0.75(-1.76 / 0.26)]$ difference for CP2 vs DP [+6.2(6.6) and +2.1(3.7)\% for $\mathrm{HI}$ and LO, respectively].

As shown in Fig. 3, the percentage of the $\mathrm{V}_{\max }$-difference in CP1 than DP showed an inversely large correlation with $\mathrm{V}_{\max }, \dot{V} \mathrm{O}_{2 \max }$ and the velocity at lactate threshold. Conversely, the percentage of the $\mathrm{V}_{\max }$-difference in CP1 than DP was largely correlated with the time-constant of the $\dot{V}$ $\mathrm{O}_{2}$ kinetics.

\section{Discussion}

The main finding of the present study was that HI, with faster $\dot{V} \mathrm{O}_{2}$ kinetics, had lower differences in $\mathrm{V}_{\text {max }}$ between $\mathrm{CP}$ and DP than LO. This observation may confirm the experimental hypothesis stating that athletes with higher aerobic capacity and faster $\dot{V} \mathrm{O}_{2}$ kinetics are able to adjust better to work rate increments typical of $\mathrm{CP}$ with short stage duration. Noticeably, $\mathrm{HI}$ had a similar $\mathrm{V}_{\max }$ in DP and CP2 (i.e., the continuous protocol with slower work rate increments) and the difference in $\mathrm{V}_{\text {max }}$ between $\mathrm{CP} 1$ and DP was lower than in LO. Lastly, the percentage of the $\mathrm{V}_{\max }$ differences between CP1 and DP were inversely correlated with $\mathrm{V}_{\max }, \dot{V} \mathrm{O}_{2 \max }$ and directly correlated to the time-constant of the $\dot{V} \mathrm{O}_{2}$ kinetics, providing further evidence that betweenprotocol $\mathrm{V}_{\max }$ differences in $\mathrm{HI}$ are minimized likely because of their faster $\dot{V} \mathrm{O}_{2}$ kinetics. 

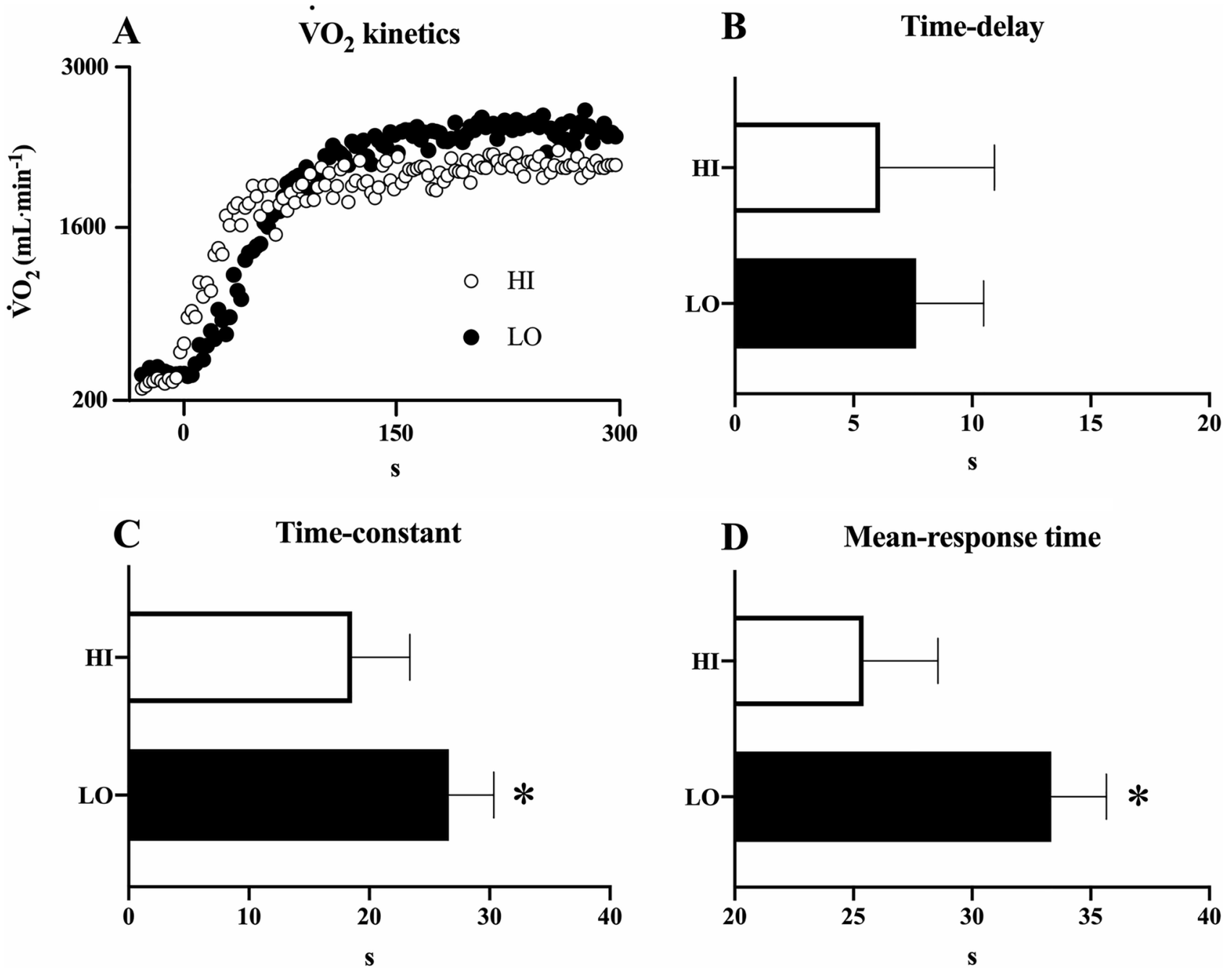

Fig. 2 The rate of $\dot{V} \mathrm{O} 2$ increase at submaximal exercise for both $\mathrm{HI}$ and LO. Panel A shows the rate of $\dot{V} \mathrm{O}_{2}$ increase ( $\dot{V} \mathrm{O}_{2}$ kinetic) for two representative subjects (HI: white circles; LO: black circles).

\section{Preliminary considerations}

The present results came with no between-protocol differences in $\dot{V} \mathrm{O}_{2 \max }$ and in the other main cardiorespiratory and metabolic parameters in both $\mathrm{HI}$ and LO. Despite some previous findings about the effects of protocol (i.e. workload vs recovery ratio) on $\dot{V} \mathrm{O}_{2 \max }$ (Vinetti et al. 2017), these findings reinforce previous data demonstrating that $\dot{V} \mathrm{O}_{2 \max }$ was independent of the protocol adopted across different incremental testing procedures (Bentley et al. 2007; Billat et al. 1996; Riboli et al. 2017). The present outcomes are in line with previous literature, in which no differences in $\dot{V}$ $\mathrm{O}_{2 \max }$ were observed between protocols in different populations, such as recreationally-active men (Kirkeberg et al. 2011), physically-active young adults (Riboli et al. 2017),
The time-delay (Panel B), the time-constant (Panel C) and the meanresponse time (Panel D) are illustrated for each subject (white circles) in $\mathrm{HI}$ (white bar) and LO (dark-grey bar) group. ${ }^{\#} \mathrm{P}<0.05$ vs $\mathrm{HI}$

semi-professional soccer players (Riboli et al. 2021) and competitive middle- and long-distance runners (Billat et al. 1996; Kuipers et al. 2003). Similar results were also found in moderately-active cyclists during cycle-ergometric evaluation (Adami et al. 2013).

\section{Maximum exercise}

The present findings demonstrate that $\mathrm{V}_{\max }$ was protocoldependent, as also previously observed (Kuipers et al. 2003; Riboli et al. 2017, 2021). The steeper the work rate increase, the higher the $\mathrm{V}_{\max }$ in both groups. In $\mathrm{LO} \mathrm{V}_{\max }$ differed in each protocol (i.e., $\mathrm{CP} 1>\mathrm{CP} 2>\mathrm{DP}$ ). Conversely, in $\mathrm{HI}$ the $\mathrm{V}_{\text {max }}$ differences between CP2 and DP were not present (i.e., $\mathrm{CP} 1>\mathrm{CP} 2=\mathrm{DP}$ ). These findings suggest that higher aerobic capacity may minimize the between-protocol $\mathrm{V}_{\max }$ 

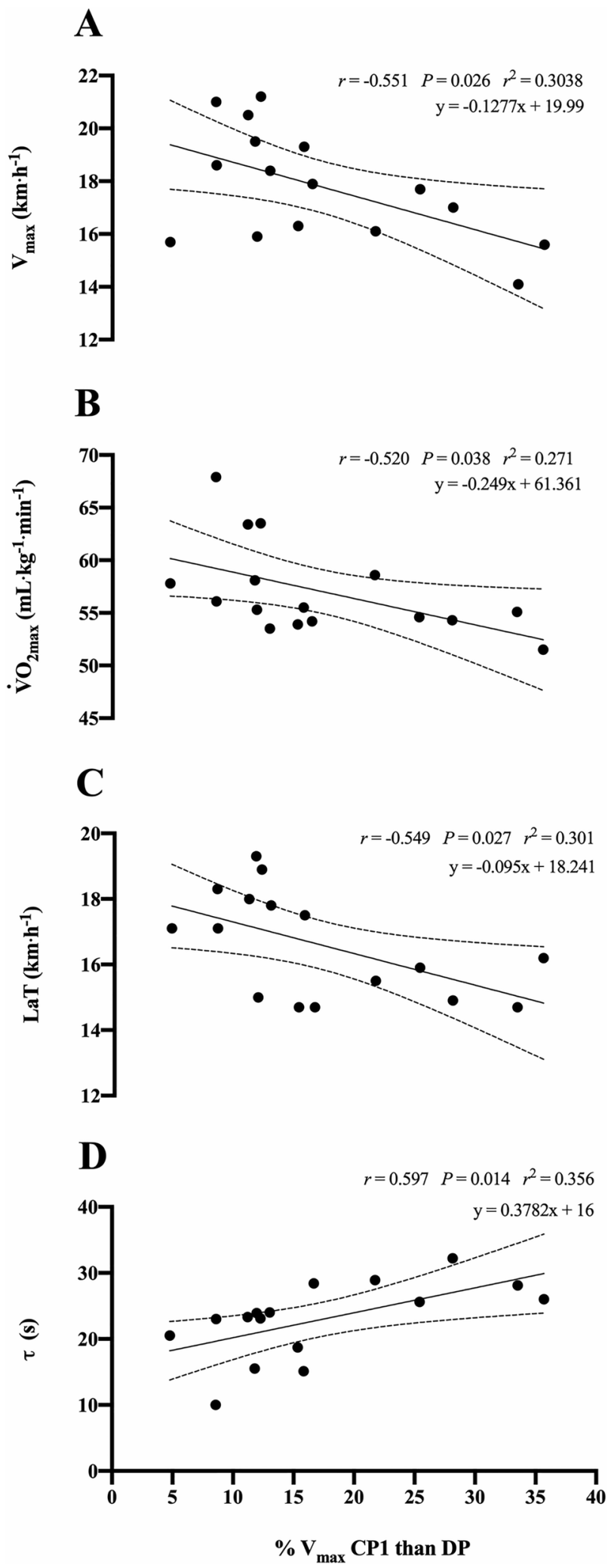

Fig. 3 Relationship between training status and the between-protocol $\mathrm{V}_{\max }$ difference. The percentage of the individual $\mathrm{V}_{\max }$-difference in CP1 than DP is related with the velocity associated with maximum oxygen uptake $\left(\mathrm{V}_{\max }\right.$, Panel A), maximum oxygen uptake ( $\dot{V} \mathrm{O}_{2 \max }$, Panel B) and lactate threshold (LaT, Panel C). Regression equations $(\mathrm{y}=\mathrm{a} \cdot \mathrm{bx}), 95 \%$ confidence intervals and correlation coefficients are also reported differences due to the faster cardiorespiratory and metabolic adjustments to match the increasing mechanical power in CP. This explanation was further supported by the faster $\dot{V} \mathrm{O}_{2}$ kinetics in $\mathrm{HI}$, in which no difference was found between $\mathrm{CP} 2$ and DP. On the contrary, in $\mathrm{LO} \mathrm{V}_{\max }$ in CP2 was higher than in DP due to the slower $\dot{V} \mathrm{O}_{2}$ kinetics. A direct comparison with previous studies is challenging, as this was the first study investigating the effect of aerobic training status on $\mathrm{V}_{\max }$. Previous studies observed a greater between-protocol difference when steeper work rate vs time increments were utilized (Kuipers et al. 2003; Riboli et al. 2017, 2021). Indeed, when comparing three CPs with 1-, 3- or 6-min stage duration in competitive middle-distance runners, $\mathrm{V}_{\max }$ was related to the slope of the work rate $v \mathrm{~s}$ velocity increments (Kuipers et al. 2003). Similar results were found when a $\mathrm{CP}$ with different work rate $v s$ velocity increments was used during cycle ergometry in active people (Adami et al. 2013) or international competitive triathletes (Bentley and McNaughton 2003). Recently, greater peak mechanical power output was found also in healthy participants using a synchronous arm crank ergometry when work rate increments were steeper (Kouwijzer et al. 2019). Interestingly, when long-distance runners were tested using $\mathrm{CP}$ with different stage duration but similar slope in the velocity $v$ s time increments (e.g., $1 \mathrm{~km} \cdot \mathrm{h}^{-1}$ increments every 2 min $v s 0.5 \mathrm{~km} \cdot \mathrm{h}^{-1}$ increments every min), no difference in $\mathrm{V}_{\max }$ was detected (Billat et al. 1996). Similar findings were observed also in sedentary men on cycle ergometer (Zhang et al. 1991).

\section{Submaximal exercise}

A faster $\dot{V} 0_{2}$ kinetics was observed in $\mathrm{HI}$ than in LO participants during the test at $10 \mathrm{~km} / \mathrm{h}$, implying a more rapid cardiorespiratory and metabolic adjustment capacity to match mechanical power increase during incremental exercise. Previous investigations observed that athletes with a high aerobic capacity, such as long- and middle-distance runners, were qualified by greater physiological characteristics in terms of faster $\dot{V} \mathrm{O}_{2}$ kinetics (Poole and Jones 2012; Coyle 1995). In top-level aerobic athletes, indeed, an extremely short time (i.e., $\sim 30$ to 40 s) is required to achieve a $\dot{V} \mathrm{O}_{2}$ steady-state (Poole and Jones 2012), while in trained healthy individuals at least 2-3 min or even more are required (Robergs 2014; Poole and Jones 2012). The present results confirm the current hypothesis demonstrating a lower betweenprotocol $\mathrm{V}_{\max }$ difference in $\mathrm{HI}$ than in LO likely due to the changes in running velocity faster than cardiorespiratory and metabolic adjustments. This was remarkably highlighted by no-differences in $\mathrm{V}_{\max }$ between $\mathrm{CP} 2$ and DP for $\mathrm{HI}$.

The between-protocol difference in the $\dot{V} \mathrm{O}_{2}$ /velocity slope, was greater in LO (large to very large) than in $\mathrm{HI}$ (trivial to moderate), leading the slope to $\mathrm{CP} 1>\mathrm{CP} 2>\mathrm{DP}$ 
and $\mathrm{CP} 1>\mathrm{CP} 2=\mathrm{DP}$ in LO and HI, respectively. High-level aerobic athletes are also qualified by better biomechanical characteristics matching with a faster $\dot{V}$ O kinetics and a higher running economy (Coyle 1995). In the present study, LO showed a reduced $\dot{V} \mathrm{O}_{2}$ /velocity slope in both $\mathrm{CP} 1$ and $\mathrm{CP} 2$ than DP, while in $\mathrm{HI}$ the difference between $\mathrm{CP} 2$ and DP disappeared. This condition typically occurs when the time to reach cardiorespiratory and metabolic equilibrium matches the change in work rate across CPs.

\section{Training status and between-protocol differences}

The between-protocol $\mathrm{V}_{\max }$ differences were inversely correlated with training status. A higher $\dot{V} \mathrm{O}_{2 \max }, \mathrm{V}_{\text {max }}$, lactate threshold and faster $\dot{V} \mathrm{O}_{2}$ kinetics provided further evidence that between-protocol $\mathrm{V}_{\max }$ differences in $\mathrm{HI}$ may be likely counteracted by their higher aerobic training status. Therefore, a more consistent $\mathrm{V}_{\max }$ across different protocols in athletes with a higher aerobic capacity was found. The knowledge of the between-protocols $\mathrm{V}_{\text {max }}$ differences could have practical implications for testing, exercise prescriptions and physiological outcomes during running activities. Different $\% \mathrm{~V}_{\max }$ were shown to lead different physiological responses by increasing or decreasing the time spent at $\sim \dot{V}$ $\mathrm{O}_{2 \max }$, a crucial factor for chronic adaptations and performance development (Buchheit and Laursen 2013). Therefore, a more consistent $\mathrm{V}_{\max }$ determination should permit a more accurate running exercise prescription in both $\mathrm{HI}$ and LO athletes.

\section{Methodological considerations}

Some methodological considerations should accompany the present investigation. First, the study of the dynamic response of metabolic and pulmonary variables upon exercise onset is strongly affected by the recording technique (Ferretti 2015). The Auchincloss algorithm (Auchincloss et al. 1966) utilized to calculate dynamic $\dot{V} \mathrm{O}_{2}$ responses requires a correct determination of the change in the amount of gas stored in the lungs over each breath. However, the algorithm estimated the end-expiratory lung volume imposing fixed pre-defined values of end-expiratory lung volumes (Ferretti 2015) leading to an impossibility of attaining a correct estimation (di Prampero and Lafortuna 1989). Subsequently, it was demonstrated a two-time improvement of the signal-to-noise ratio in breath-by-breath alveolar gas transfer (Capelli et al. 2001) and a lower dynamic response (Cautero et al. 2002) using Grønlund algorithm. However, despite such algorithm improvements, the aforementioned issue could not be fixed (Ferretti 2015). Secondly, despite a stepwise interpolation procedure was proposed to improve the time-constant calculation (Lamarra et al. 1987), a slightly higher time-constant than the interpolation interval still remains. Therefore, at least in the light exercise domain, mere stacking of multiple repetitions was proposed if the data were from the same $\dot{V} \mathrm{O}_{2}$ on rest-to-exercise transient (Bringard et al. 2014; Francescato et al. 2014b, a). As such, attempts at improving the time resolution beyond the singlebreath duration could rely only on computational manipulations, such as superimposition of several trials and interpolation procedures (Francescato et al. 2014a; Francescato and Cettolo 2020).

Lastly, the present findings open to new future perspectives. During submaximal running bouts, the time shift between velocity and $\dot{V} \mathrm{O}_{2}$ could be calculated knowing the time constant of the $\dot{V} \mathrm{O}_{2}$-on kinetics. Therefore, a mathematical modeling would possibly provide a calibration equation for $\mathrm{V}_{\max }$ correction in $\mathrm{CP} 1$ and $\mathrm{CP} 2$ with respect to DP.

\section{Practical considerations}

The between-protocol $\mathrm{V}_{\max }$ differences in CP1 $(+18 \%$ and $+13 \%$ than DP in LO and HI, respectively) and CP2 ( $+6 \%$ than DP in LO) should be considered for both athletes aerobic profiling and exercise prescription. These results suggest that in LO a protocol with more than 2 min stage durations is required for the metabolic power to match the mechanical power. In HI, a 2-min stage duration may be suitable and can be consistently utilized within sport contexts. When shorter stage durations are mandatorily required (e.g., 1-min), a misestimate $\mathrm{V}_{\max }$ should be considered to plan accurately high-intensity exercises in both $\mathrm{HI}$ and LO. Indeed, different $\%-\mathrm{V}_{\max }$ are suggested to increase the time spent at $\sim \dot{V} \mathrm{O}_{2 \max }$ during high-intensity interval or intermittent exercises (e.g., $110 \%$ to $130 \%-\mathrm{V}_{\max }$ for short-intervals exercises or $130 \%$ to $160 \%-\mathrm{V}_{\max }$ for repeated sprint trainings) (Buchheit and Laursen 2013). Therefore, when short intervals exercises (e.g., $\sim 110 \% \mathrm{~V}_{\max }$ ) are prescribed, 18\% of $\mathrm{V}_{\max }$ difference in CP1 vs DP for LO should induce an unexpected greater anaerobic involvement leading to acute physiological responses similar to a running exercise at $\sim 130 \%-\mathrm{V}_{\max }$ (i.e., $\sim 25 \mathrm{~km} \cdot \mathrm{h}^{-1}$ instead of $\sim 21 \mathrm{~km} \cdot \mathrm{h}^{-1}$ ). Similar differences between desired and actual physiological responses could be found across any $\%-\mathrm{V}_{\max }$ within both longer and shorter running exercises. Neglected betweenprotocol $\mathrm{V}_{\max }$ differences may mislead acute physiological responses (e.g., more aerobic or anaerobic contribution) and possibly negatively affect the training adaptations, especially within-athletes with lower training status. Therefore, the knowledge of the between-protocol differences may help practitioners to properly manage different testing modalities and to adjust the $\%-\mathrm{V}_{\max }$ when intermittent or interval running-based exercises are prescribed. 


\section{Conclusions}

As previously observed, CP and DP can be used interchangeably to assess $\dot{V} \mathrm{O}_{2 \max }$, but not $\mathrm{V}_{\text {max }}$ (Riboli et al. 2017, 2021). We demonstrate here that aerobic training status can influence the magnitude of the between-protocol differences in $\mathrm{V}_{\max }$ assessment. When different protocols are utilized to determine $\mathrm{V}_{\max }$, between-protocol differences exist, especially in CPs $v s$ DP in which a matching between metabolic and mechanical power clearly occurs. These $\mathrm{V}_{\max }$ differences should be considered when athletes with different aerobic training status are tested. The $\mathrm{V}_{\text {max }}$ difference between CPs and DP disappeared in HI during $\mathrm{CP} 2$, suggesting that a protocol with at least 2-min stage duration may be sensitive enough in athletes with a greater aerobic capacity, while differences still exist across participants with lower aerobic training status for which at least 3-min stage duration seems required. These between-protocol $\mathrm{V}_{\max }$ differences should be considered when athletes with different aerobic capacity are tested because they may affect the testing outcomes and training prescriptions.

Acknowledgements The authors would like to thank all the participants for their commitment.

Author contribution All authors contributed to the study. Conceptualization: AR, FE, Data collection: AR, SR, EL, MB, EC, GC. Data analysis: AR, SR. Methodology: AR, FE. Visualization: AR, GC. Writing - original draft: AR, FE. Writing - review \& editing: AR, FE.

Funding Open access funding provided by Università degli Studi di Milano within the CRUI-CARE Agreement. The authors have no funding supports to declare.

Availability of data and material Data and materials are available on request to the corresponding author.

Code availability Protocol \#102/14.

\section{Declarations}

Conflict of interest The authors have no conflicts of interest/competitive interests to declare.

Ethical approval The ethics committee of the local University approved the study (protocol \#102/14) which was performed in accordance with the principles of the Declaration of Helsinki (1964 and updates).

Consent to participate All participants gave their written consent after a full explanation of the purpose of the study and the experimental design.

Consent for publication All Authors give their consensus for publication.

Open Access This article is licensed under a Creative Commons Attribution 4.0 International License, which permits use, sharing, adaptation, distribution and reproduction in any medium or format, as long as you give appropriate credit to the original author(s) and the source, provide a link to the Creative Commons licence, and indicate if changes were made. The images or other third party material in this article are included in the article's Creative Commons licence, unless indicated otherwise in a credit line to the material. If material is not included in the article's Creative Commons licence and your intended use is not permitted by statutory regulation or exceeds the permitted use, you will need to obtain permission directly from the copyright holder. To view a copy of this licence, visit http://creativecommons. org/licenses/by/4.0/.

\section{References}

Adami A, Sivieri A, Moia C, Perini R, Ferretti G (2013) Effects of step duration in incremental ramp protocols on peak power and maximal oxygen consumption. Eur J Appl Physiol 113(10):2647-2653. https://doi.org/10.1007/s00421-013-2705-9

Anderson T (1996) Biomechanics and running economy. Sports Med 22(2):76-89. https://doi.org/10.2165/00007256-19962 2020-00003

Auchincloss JH Jr, Gilbert R, Baule GH (1966) Effect of ventilation on oxygen transfer during early exercise. J Appl Physiol 21(3):810 818. https://doi.org/10.1152/jappl.1966.21.3.810

Barstow TJ (1991) Mole PA (1991) Linear and nonlinear characteristics of oxygen uptake kinetics during heavy exercise. J Appl Physiol 71(6):2099-2106. https://doi.org/10.1152/jappl.1991.71.6.2099

Bentley DJ, McNaughton LR (2003) Comparison of W(peak), $\mathrm{VO}$ 2(peak) and the ventilation threshold from two different incremental exercise tests: relationship to endurance performance. J Sci Med Sport 6(4):422-435

Bentley DJ, Newell J, Bishop D (2007) Incremental exercise test design and analysis: implications for performance diagnostics in endurance athletes. Sports Med 37(7):575-586

Bernard O, Ouattara S, Maddio F, Jimenez C, Charpenet A, Melin B, Bittel J (2000) Determination of the velocity associated with VO2max. Med Sci Sports Exerc 32(2):464-470

Billat VL, Hill DW, Pinoteau J, Petit B, Koralsztein JP (1996) Effect of protocol on determination of velocity at $\mathrm{VO} 2$ max and on its time to exhaustion. Arch Physiol Biochem 104(3):313-321. https://doi. org/10.1076/apab.104.3.313.12908

Bringard A, Adami A, Moia C, Ferretti G (2014) A new interpolationfree procedure for breath-by-breath analysis of oxygen uptake in exercise transients. Eur J Appl Physiol 114(9):1983-1994. https:// doi.org/10.1007/s00421-014-2920-z

Buchheit M, Laursen PB (2013) High-intensity interval training, solutions to the programming puzzle: Part I: cardiopulmonary emphasis. Sports Med 43(5):313-338. https://doi.org/10.1007/ s40279-013-0029-x

Capelli C, Cautero M, di Prampero PE (2001) New perspectives in breath-by-breath determination of alveolar gas exchange in humans. Pflugers Arch 441(4):566-577. https://doi.org/10.1007/ s004240000429

Cautero M, Beltrami AP, di Prampero PE, Capelli C (2002) Breathby-breath alveolar oxygen transfer at the onset of step exercise in humans: methodological implications. Eur J Appl Physiol 88(3):203-213. https://doi.org/10.1007/s00421-002-0671-8

Coyle EF (1995) Integration of the physiological factors determining endurance performance ability. Exerc Sport Sci Rev 23(1):25-64

di Prampero PE, Lafortuna CL (1989) Breath-by-breath estimate of alveolar gas transfer variability in man at rest and during exercise. 
J Physiol 415:459-475. https://doi.org/10.1113/jphysiol.1989. sp017731

Duncan GE, Howley ET, Johnson BN (1997) Applicability of VO2max criteria: discontinuous versus continuous protocols. Med Sci Sports Exerc 29(2):273-278

Dupont G, Millet GP, Guinhouya C, Berthoin S (2005) Relationship between oxygen uptake kinetics and performance in repeated running sprints. Eur J Appl Physiol 95(1):27-34. https://doi.org/10. 1007/s00421-005-1382-8

Ferretti G (2015) Energetics of muscular exercise. Springer, Heidelberg. https://doi.org/10.1007/978-3-319-05636-4

Fletcher JR, Esau SP (2009) Macintosh BR (2009) Economy of running: beyond the measurement of oxygen uptake. J Appl Physiol 107(6):1918-1922. https://doi.org/10.1152/japplphysiol.00307. 2009

Francescato MP, Cettolo V (2020) The 1-s interpolation of breth-bybreath $\mathrm{O} 2$ uptake data to determine kinetic parameters: the misleading procedure. Sport Sci Health 16:193. https://doi.org/10. 1007/s11332-019-00602-9

Francescato MP, Cettolo V, Bellio R (2014a) Assembling more O(2) uptake responses: is it possible to merely stack the repeated transitions? Respir Physiol Neurobiol 200:46-49. https://doi.org/10. 1016/j.resp.2014.06.004

Francescato MP, Cettolo V, Bellio R (2014b) Confidence intervals for the parameters estimated from simulated $\mathrm{O} 2$ uptake kinetics: effects of different data treatments. Exp Physiol 99(1):187-195. https://doi.org/10.1113/expphysiol.2013.076208

Hopkins WG, Marshall SW, Batterham AM, Hanin J (2009) Progressive statistics for studies in sports medicine and exercise science. Med Sci Sports Exerc 41(1):3-13. https://doi.org/10.1249/MSS. 0b013e31818cb278

Jones AM, Grassi B, Christensen PM, Krustrup P, Bangsbo J, Poole DC (2011) Slow component of VO2 kinetics: mechanistic bases and practical applications. Med Sci Sports Exerc 43(11):20462062. https://doi.org/10.1249/MSS.0b013e31821fcfc1

Kirkeberg JM, Dalleck LC, Kamphoff CS, Pettitt RW (2011) Validity of 3 protocols for verifying VO2 max. Int J Sports Med 32(4):266270. https://doi.org/10.1055/s-0030-1269914

Kouwijzer I, Valize M, Valent LJM, Grandjean Perrenod Comtesse P, van der Woude LHV, de Groot S (2019) The influence of protocol design on the identification of ventilatory thresholds and the attainment of peak physiological responses during synchronous arm crank ergometry in able-bodied participants. Eur J Appl Physiol 119(10):2275-2286. https://doi.org/10.1007/ s00421-019-04211-9

Kuipers H, Rietjens G, Verstappen F, Schoenmakers H, Hofman G (2003) Effects of stage duration in incremental running tests on physiological variables. Int J Sports Med 24(7):486-491. https:// doi.org/10.1055/s-2003-42020

Lamarra N, Whipp BJ, Ward SA (1987) Wasserman K (1987) Effect of interbreath fluctuations on characterizing exercise gas exchange kinetics. J Appl Physiol 62(5):2003-2012. https://doi.org/10.1152/ jappl.1987.62.5.2003

Noakes TD (1988) Implications of exercise testing for prediction of athletic performance: a contemporary perspective. Med Sci Sports Exerc 20(4):319-330. https://doi.org/10.1249/00005768-19880 $8000-00001$
Pedro RE, Milanez VF, Boullosa DA, Nakamura FY (2013) Running speeds at ventilatory threshold and maximal oxygen consumption discriminate futsal competitive level. J Strength Cond Res 27(2):514-518. https://doi.org/10.1519/JSC.0b013e3182542661

Poole DC, Jones AM (2012) Oxygen Uptake Kinetics Compr Physiol 2(2):933-996. https://doi.org/10.1002/cphy.c100072

Poole DC, Richardson RS (1997) Determinants of oxygen uptake implications for exercise testing. Sports Med 24(5):308-320

Poole DC, Wilkerson DP, Jones AM (2008) Validity of criteria for establishing maximal $\mathrm{O} 2$ uptake during ramp exercise tests. Eur J Appl Physiol 102(4):403-410. https://doi.org/10.1007/ s00421-007-0596-3

Rampinini E, Bishop D, Marcora SM, Ferrari Bravo D, Sassi R, Impellizzeri FM (2007) Validity of simple field tests as indicators of match-related physical performance in top-level professional soccer players. Int J Sports Med 28(3):228-235. https://doi.org/10. 1055/s-2006-924340

Riboli A, Ce E, Rampichini S, Venturelli M, Alberti G, Limonta E, Veicsteinas A, Esposito F (2017) Comparison between continuous and discontinuous incremental treadmill test to assess velocity at VO2max. J Sports Med Phys Fitness 57(9):1119-1125. https:// doi.org/10.23736/S0022-4707.16.06393-3

Riboli A, Rampichini S, Ce E, Limonta E, Coratella G, Esposito F (2019) Effect of ramp slope on different methods to determine lactate threshold in semi-professional soccer players. Res Sports Med 27(3):326-338. https://doi.org/10.1080/15438627.2018.1523790

Riboli A, Coratella G, Rampichini S, Limonta E, Esposito F (2021) Testing protocol affects the velocity at VO2max in semi-professional soccer players. Res SportsMed.https://doi.org/10.1080/15 438627.2021.1878460.https://doi.org/10.1080/15438627.2021. 1878460

Robergs RA (2014) A critical review of the history of low- to moderate-intensity steady-state VO2 kinetics. Sports Med 44(5):641653. https://doi.org/10.1007/s40279-014-0161-2

Rossiter HB, Kowalchuk JM (2006) Whipp BJ (2006) A test to establish maximum $\mathrm{O} 2$ uptake despite no plateau in the $\mathrm{O} 2$ uptake response to ramp incremental exercise. J Appl Physiol 100(3):764-770. https://doi.org/10.1152/japplphysiol.00932.2005

Vinetti G, Fagoni N, Taboni A, Camelio S, di Prampero PE, Ferretti $G$ (2017) Effects of recovery interval duration on the parameters of the critical power model for incremental exercise. Eur J Appl Physiol 117(9):1859-1867. https://doi.org/10.1007/ s00421-017-3662-5

Zhang YY, Johnson MC 2nd, Chow N, Wasserman K (1991) Effect of exercise testing protocol on parameters of aerobic function. Med Sci Sports Exerc 23(5):625-630

Ziogas GG, Patras KN, Stergiou N, Georgoulis AD (2011) Velocity at lactate threshold and running economy must also be considered along with maximal oxygen uptake when testing elite soccer players during preseason. J Strength Cond Res 25(2):414-419. https:// doi.org/10.1519/JSC.0b013e3181bac3b9

Publisher's Note Springer Nature remains neutral with regard to jurisdictional claims in published maps and institutional affiliations. 